\title{
Interdisciplinary Perspectives on Poverty Measurement, Epistemic Injustices and Social Activism
}

\author{
Valentin Beck, Henning Hahn, and Robert Lepenies
}

\begin{abstract}
As we enter the 2020s, global poverty is still a grave and persistent problem. Alleviating and eradicating poverty within and across the world's societies requires a thorough understanding of its nature and extent. Although economists still standardly measure absolute and relative poverty in monetary terms, a consensus is emerging that poverty is a socially relational problem involving deprivations in multiple dimensions, including health, standard of living, education and political participation. The anthology Dimensions of Poverty advances the interdisciplinary debate on multidimensional poverty, and features contributions from leading international experts and early career researchers (including from the Global South). This introductory chapter gives an overview of formative debates, central concepts and key findings. While monetary poverty measures are still dominant in public and academic debate, their explanatory power has been drawn into question. We discuss relevant criticisms before outlining the normative concepts that can inform both multidimensional poverty and monetary measures, including basic capabilities, basic needs and social primary goods. Next, we introduce several influential multidimensional poverty indices, including the Human Development Index and the Multidimensional Poverty Index. The anthology shows in detail how such measures can be improved, from a variety of disciplinary perspectives. It shows that there are different methods of poverty research that require further investigation, including participatory studies, (value) surveys, public consensus building, the constitutional approach, and financial diaries. Finally, we show that there is an ongoing problem
\end{abstract}

\footnotetext{
V. Beck $(\varangle) \cdot$ H. Hahn

Institute of Philosophy, Freie Universität Berlin, Berlin, Germany

e-mail: valentin.beck@fu-berlin.de; hehahn@web.de

R. Lepenies

Helmholtz Centre for Environmental Research GmbH - UFZ, Leipzig, Sachsen, Germany

e-mail: robert.lepenies@eui.eu
} 
of epistemic asymmetries in global poverty research, and discuss responsibility for addressing poverty, including the responsibilities of academics. The remainder of the chapter is dedicated to a more detailed preview of the volume's 20 contributions, which are assembled along the following five themes: (I) poverty as a social relation; (II) epistemic injustices in poverty research; (III) the social context of poverty; (IV) measuring multidimensional poverty; and (V) country cases.

Keywords Poverty $\cdot$ Concept of poverty $\cdot$ Multidimensional poverty $\cdot$ Poverty measurement $\cdot$ Epistemic injustice $\cdot$ Social activism

\section{The Importance of Interdisciplinary Poverty Research}

As we enter the 2020s, a large part of humanity still lives in dire poverty. While there has been a spectacular increase of resources at the top of the income spectrum over the last few decades, economic improvements for the less and least well-off have lagged behind. How we judge the success of past and current efforts at poverty alleviation depends not only on what can be legitimately expected, but also on the methodologies we use to measure poverty. According to the World Bank, the proportion of the world's "extremely poor", narrowly defined as those who live on less than US\$ 1.90 a day (with 2011 purchasing power parity levels), has dropped significantly over the last decades. However, this monetary baseline is widely regarded as too low, which is now implicitly conceded even by its creators (see World Bank 2018, pp. 67 ff.). Nevertheless, the number of people below this lowest of benchmarks still remains in the hundreds of millions, and has in fact increased in some regions of the world, particularly in Sub-Saharan Africa (ibid., p. 2). Furthermore, it is now estimated that the goal of the complete eradication of extreme poverty, enshrined in the UN's 2030 agenda, will not be met-at least not without radical policy changes in the affected regions (ibid., p. 3). This forecast does not account for additional goals, such as the reduction of relative and multidimensional poverty, which is implied by the Sustainable Development Goal (SDG) 1 of "end[ing] poverty in all its forms everywhere". The gravity and persistence of poverty can be revealed by applying slightly higher monetary benchmarks. In 2015, a quarter of the world's population was living on less than US\$ 3.20 a day, while almost half were living on less than US\$ 5.50 a day (ibid., p. 67).

Poverty is widely regarded as a socioeconomic injustice that requires resolute alleviation measures coordinated through political action. Determining the nature and extent of absolute and relative poverty within and across states is crucial, since our definition and understanding of poverty inform policy and motivate political action. However, poverty measurement is an unexpectedly contested issue. The complex technicalities of measurement efforts are only one side of the story. The other is that "poverty" is a genuinely normative term: Judgments that refer to 
instances of poverty in the world have not only a descriptive component, but also an evaluative one, besides which they are often combined with prescriptions about who should do what to alleviate poverty. The disagreements begin with defining poverty itself. Poverty may be defined broadly as an economic deficiency that causes deprivations in well-being. But this definition is not yet operational, and disguises a range of more substantive normative controversies. It leaves open precisely which deprivations in well-being are necessary for a person or a subpopulation to be considered poor, as not all deprivations will be deemed relevant. For example, if a person does not enjoy unrestrained access to clean outdoor air due to pervasive man-made environmental pollution, then she is severely deprived in wellbeing, but she will not necessarily be considered poor; she might for example be affluent and therefore able to buy an air filtration device for her home, in contrast to people with lower incomes who cannot purchase such devices, or those who lack shelter altogether. Poverty occurs in historically changing social contexts, which necessitates continuous reinterpretation of what it means to be poor in these contexts. What will be regarded as poverty is at least in part dependent on what is customary in a given society. While according to Adam Smith's famous observation, being able to purchase a linen shirt was necessary to appear in public without shame in his time (see Smith 1976 [1776], book 4, ch. 2), the customs of present societies necessitate access to a different range of material goods in order to avoid similar social stigmatization.

One of the more momentous insights for those engaged in poverty research is that determining the nature and extent of poverty in the world is a truly interdisciplinary challenge. Researchers of different disciplines are mutually reliant on one another. On the one hand, empirical poverty research should be informed by sound methodologies that include transparent conceptual and normative assumptions. Professional philosophers who are trained in analysing and justifying normative concepts can contribute to this task. On the other hand, philosophical research on poverty must not be a purely abstract undertaking, detached from empirical research. Philosophers must take into account evidence about the varied forms of deprivation that occur within different social contexts, including the perceptions and evaluations of people who are affected by these deprivations.

With this anthology, we seek to advance the interdisciplinary debate on poverty by focussing on its conceptualization and measurement, on the epistemic injustices in poverty research, and on poverty-related social activism. The unifying theme connecting this volume's contributions is that poverty needs to be understood not only as a multidimensional, but also as a socially relational phenomenon, and that this dual understanding can improve existing efforts toward measuring and alleviating poverty. In order to advance the debate on poverty, we provide a forum for much needed dialogue between philosophers and more empirically oriented researchers, because philosophically sound analysis of and truly global research on poverty's social embeddedness must go hand in hand. This book gathers original articles by eminent scholars, whose earlier studies have been formative for poverty research, but also by younger researchers with diverse scientific, cultural and geographical backgrounds, including scholars from the Global South, whose voices have been 
notoriously ignored and overlooked for too long. ${ }^{1}$ The anthology is interdisciplinary in a double sense: Not only do its contributors come from different disciplines, including philosophy, development economics, political science and sociology, but many of the contributions to this volume are also interdisciplinary in themselves, including both reflection on the philosophical (conceptual and normative) aspects of poverty, and empirical research. Furthermore, several contributions can be considered transdisciplinary as their authors draw from their expertise of discussing and shaping poverty metrics in dialogue with policy-makers (see Alkire this volume; Burchi et al. this volume; Dotter and Klasen this volume; Godinot and Walker this volume; Reddy this volume; and Wolff this volume).

Towards the end of this introduction, we will preview the volume's structure and content in more detail (see Sect. 3). Beforehand, we will provide some background knowledge by giving an overview of formative debates in poverty research (see Sect. $2 \mathrm{a}-\mathrm{c}$ ). These debates are aligned with three themes, namely: (a) conceptualizing and measuring poverty in different societies and across the world; (b) epistemic asymmetries in global poverty research; and (c) responsibilities for addressing poverty, including reflections on the specific responsibilities of academics engaged in poverty research.

\section{Formative Debates in Poverty Research}

\section{(a) The conceptualization and measurement of poverty}

Adequately measuring poverty requires not only reliable data, but also a sound methodology that includes a plausible poverty metric. Such a metric should be based on a justifiable normative theory of what exactly people in poverty lack (in virtue of being poor). It is an evaluative standard that allows classification of those who are poor within different social contexts (be it in specific societies or the world at large). A poverty metric can be based on an absolute threshold standard or on a relative standard that defines poverty by referencing levels of well-being in a given society. These standards can be measured in either purely monetary terms or more broadly by referencing non-monetary indicators as well.

Monetary metrics still constitute the most well-known type of poverty standard. According to monetary metrics, a person is poor if their income or consumption expenditures fall below a certain limit, which can be a fixed number, or a ratio based on the level of economic prosperity within a social context. Monetary metrics are standardly applied in national contexts, but the most well-known contemporary

\footnotetext{
${ }^{1}$ Most contributions to this volume are based on presentations given at the conference "Dimensions of Poverty", which took place at the Haus der Kulturen der Welt (HKW) in June 2017 in Berlin. More than 30 presentations were selected following an open and international call for papers which resulted in over 100 submissions from 33 countries on six continents. The conference was generously sponsored by the HKW and the Centre for Advanced Studies "Justitia Amplificata", funded by the Deutsche Forschungsgemeinschaft (DFG).
} 
examples are the World Bank's global poverty measures, briefly mentioned above and alternatively referred to as "international poverty lines". In the year of 1990, the Bank originally set a US\$ 1 a day threshold in their estimates of the total number of people who live in extreme poverty worldwide. It has adjusted this lowest international poverty line over the years-to US\$ 1.25 a day in 2008 and to US\$ 1.90 a day in 2015. The World Bank has asserted that these adjustments, intended to account for newly available data and changes in purchasing power, provide for continuity, so that estimates of increases and decreases of the number of persons who live in extreme poverty remain consistent over time.

However, the explanatory power of the World Bank's monetary measure has been drawn into doubt. Several lines of criticism can be distinguished. ${ }^{2}$ To start with, it has been argued that the World Bank's methodology does not allow for consistent estimates of the decreases or increases of poverty over time, and that the number of extremely poor people is calculated with unrepresentative baskets of goods that yield inaccurate purchasing power parities. It has also been objected that the World Bank's numbers are based on household surveys, which obscure inequalities in the distribution of resources within households-usually to the detriment of women and children. Furthermore, it has been argued that the World Bank's poverty line is too low, leading to a general underestimation of the extent of extreme poverty in the world. ${ }^{3}$ A final criticism is that even the most reliable information about individuals' income and purchasing power only allows for limited conclusions about the quality of the life these individuals enjoy, as innate individual differences as well as differences in social, geographical and cultural environments have a considerable influence on the financial resources needed to lead a minimally good life.

This last criticism concerns not only the World Bank's global poverty measures, but all monetary standards, including those designed to measure relative income poverty. The latter standards typically classify those as relatively poor whose income is below $50 \%$ or $60 \%$ of the median in a given context. This type of poverty measure is sometimes criticized for not being universally applicable. Imagine a well-educated and materially abundant society, in which all members have high incomes. Now suppose the incomes of half of the population increase by $50 \%$ over the course of 10 years - say, due to a rise in shares of a private pension fund-while the incomes of the other half have stagnated. While there is an increase in inequality, the above monetary measure for relative income poverty suggests that there is also an increase in poverty, which might seem counterintuitive. The upshot is that poverty should be conceptually distinguished from economic inequality (see Sen 1981, p. 15). This does not mean that poverty does not have a comparative dimension, nor that economic inequalities are unproblematic. Since some forms of material inequality result in problematic forms of social exclusion, poverty measurement should generally take into account relative deprivations next to absolute ones, even if the latter

\footnotetext{
${ }^{2}$ For more extensive discussion of the following criticisms, see Reddy and Pogge (2010), Wisor et al. (2014), Reddy and Lahoti (2016), and Reddy (this volume).

${ }^{3}$ See references given in fn. 2, and Hickel (2016); see World Bank (2018) for the introduction of more expansive monetary measures.
} 
constitute the core of the phenomenon (ibid., p. 17). More crucially still, monetary indicators should not be taken as the sole measures of poverty, because we must take into account a range of aspects that cannot easily be captured in monetary terms; these include access to and enjoyment of adequate food and clothing, clean air and drinking water, healthcare and education, and political participation. Implicitly multidimensional poverty measures have been around for a long time (see e.g. Booth 1903, Rowntree 1901, and Townsend 1954, 1979). More recently, Amartya Sen has provided one of the most forceful and influential critiques of purely monetary understandings of poverty. In collaboration with Martha Nussbaum, he developed the capability approach (see e.g. Sen 1999, Nussbaum 2000) and thus paved the way for broad acceptance of multidimensional understandings of poverty. The capability approach can be used as a normative framework for the measurement not only of poverty, but of human well-being more generally. It competes with a range of other such conceptual frameworks, including welfarist, needs-based and goodsbased standards.

Welfarism takes individual utility (or happiness, or pleasure, in older formulations) as the elementary unit of measurement, as in utilitarian doctrines. This is problematic for the capability theorist due to the predominantly subjective understanding of utility. Humans generally adapt their preferences and conceptions of the good life to their specific circumstances, and those living at or close to the subsistence level are known to adapt to the adverse conditions that they face by lowering their expectations (known by development economists as the "problem of adaptive preferences"). Even in the absence of external coercion, poor peoples' choices between alternate options are gravely constrained (see e.g. Sen 1999, ch. 3). It is not enough to look at mental states in terms of subjective preference fulfilment in order to measure their quality of life. What's needed is a more reliable, objective measure. For Sen and Nussbaum, human capabilities are the preferable metric, understood as opportunities for realizing certain objectively valuable functionings, such as: being adequately nourished; being educated; being assisted by medical professionals in a situation of need; and leading a long and healthy life, among many other things that humans are or do. The capability approach does not say that people must fulfil all these intrinsically and instrumentally valuable functionings, but that it should be at least possible for them to do so if they wish (in the sense of possessing corresponding positive freedoms). For example, those who voluntarily fast or participate in a hunger strike, such as Ghandi, have the capacity to nourish themselves adequately, but choose not to. This sets them apart from hundreds of millions of chronically undernourished humans who are unable to escape their state of extreme deprivation due to external circumstances (see e.g. Sen 1999, and Nussbaum 2011, p. 25). The capability approach defines poverty as deprivation of the ability to achieve functionings that are central to a good life (see Sen 1999, ch. 4).

Needs-based approaches can overlap significantly with the capability approach, if needs are understood not subjectively, but as objective requirements for a good life (see e.g. Brock 1998). However, within needs-based approaches, there seems to be a lack of comparable emphasis on the freedoms to achieve objectively valuable functionings. A possible objection is that putting the concepts of needs (as opposed 
to that of capabilities) at the centre can lead to a problematic demotion of human beings to passive recipients of care. For what ultimately seems to matter in poverty alleviation is not only that people function well and satisfy their needs, but that they become able do so out of their own efforts.

Goods-based approaches propose to measure well-being in terms of the availability of certain bundles of material or immaterial "goods" or "resources". A prominent example is Rawls's social primary goods, understood as all-purpose goods for pursuing different rational life plans (see Rawls 1999 [1971], pp. 78-81 and ch. VII) or, in other words, "things that rational persons want whatever else they want" (ibid., p. xiii). Rawls's primary goods metric also fulfils the requirement of multidimensionality, because it includes not only material goods, such as income and wealth, but also immaterial goods, such as social and political rights, basic freedoms, professional opportunities and the social bases of self-respect. However, capability theorists have argued that the primary goods metric is not sensitive enough to the differing abilities of individuals to convert these goods into valuable functionings. For example, someone with a physical disability that prevents them from walking would require a different set of material goods to achieve mobility than someone without such a disability. In return, the primary goods metric is sometimes defended by saying that it provides a theory of the good that fulfils the neutrality requirements for liberal societies, while the capability approach requires working with an essentialist hierarchy of capabilities. However, while Nussbaum has proposed a concrete list of capabilities (see e.g. Nussbaum 2011, 33 f.), Sen has in fact emphasized the central role of public reasoning for concretizing and applying the capability approach (see e.g. Sen 2009).

Despite the fundamental differences between the aforementioned philosophical views on how to measure well-being, there is room for a consensus on at least some poverty-related questions. Different accounts, including refined versions of needsbased, goods-based and capability approaches, can all live up to the desideratum of multidimensionality. They all advise developing poverty measures that mirror important dimensions, which arguably include health, education, standard of living, political participation and financial security. They can also agree on more practical matters, such as that social institutions must provide safe access to various instrumental goods, which in turn allows for the realization of basic capabilities and the fulfilment of elementary needs. The aforementioned theories only diverge when it comes to which of these three aspects should constitute the fundamental unit for measuring human well-being and poverty. Methodologies for measuring poverty always involve normative assumptions. As such, these assumptions will likely remain contested to some extent, but there are still more and less plausible views of what kinds of human deprivation are constitutive of poverty.

It is one thing to determine the right fundamental metric for poverty measurement, and another to draw conclusions about how to improve existing poverty measures for different social contexts. It has already been suggested that developing justifiable multidimensional poverty measures is a socially important exercise which can guide more effective poverty alleviation. The above-mentioned criticisms of the World Bank's global poverty measure do not imply, however, that monetary 
measures should be abandoned altogether. They do imply, first, that monetary measures must be based on normatively plausible and transparent assumptions (see Reddy this volume), so that indicators for income and purchasing power are more informative instruments for policy design. Second, gathering reliable and methodologically sound data on income poverty is not the whole story. Rather, these indicators must be complemented and integrated with comprehensive non-monetary indicators for poverty's various dimensions. In a recent report, the World Bank acknowledged both of these general concerns (see World Bank 2018). More specifically, it now concedes that the following three things are important: (i) going beyond monetary measures and working with a broader understanding of poverty (ibid., ch. 4); (ii) measuring monetary poverty beyond the unit of household income and gathering data that actually allows this (ibid., ch. 5); and (iii) working with higher standards of monetary poverty that complement the very low threshold of US\$1.90 per day (ibid., ch. 3).

Next to the more foundational theoretical questions and controversies, there are also various practical challenges for poverty measurement. One of those challenges is gathering reliable and comprehensive data on capabilities, which is significantly more difficult than gathering data on related functionings, and much more difficult than collecting data on related resources. Such difficulties will more likely present themselves in some dimensions than in others, as for example in the education dimension (see Dotter and Klasen this volume). Those engaged in poverty research must take such practical difficulties into account when designing poverty measures. The contributions to this volume by those who focus on the more technical side of poverty measurement-some of whom have been at the forefront of the debate on poverty measurement-are reflective of such challenges (see also Sect. 3 in this introduction, and the contributions in Part IV of this volume).

There are by now several established poverty indexes that have been developed in response to the plea for multidimensional poverty measurement. The Human Development Index (HDI), developed by Amartya Sen and Mahbub ul Haq, constituted an early attempt to move beyond purely economic assessments of human development. The HDI is a composite index that ranks a country's level of development along the dimensions of life expectancy, education and per capita income. It has been used in the Human Development Report (HDR), launched by the United Nations Development Program (UNDP) on the initiative of Sen and ul Haq. In 2010, the HDR used a new composite index, named the Inequality-Adjusted Human Development Index (IHDI), which derives from the HDI but accounts for countrywide inequalities in health, education and incomes. The Human Poverty Index (HPI), on the other hand, focusses more specifically on deprivations in health, education and income at the level of countries, and was first introduced as a complement to the HDI in 1997's HDR.

In 2010, the HPI was replaced by the Global Multidimensional Poverty Index (MPI), which was developed by the Oxford Human Development Initiative (OPHI) - led by Sabina Alkire (see Alkire this volume) and James Foster-and the UNDP. The global MPI currently covers 105 countries or $77 \%$ of the world's population (representing 5.7 billion people), $23 \%$ or 1.3 billion of whom were catego- 
rized as multidimensionally poor in 2018. The global MPI uses information from ten indicators that mirror the HDI's and MPI's three poverty dimensions, namely health, education and living standards. The MPI currently represents the most differentiated global poverty measure and has undergone regular updates and a more extensive revision in 2018 to adapt it more closely to the SDGs (see Alkire et al. 2018). Next to the global MPI, which currently allows for comparisons of poverty across 105 countries, there are also national MPIs, which are based on the same methodology, but which more closely reflect the particularities of the specific countries that are covered.

The above-mentioned indexes have contributed to a more profound understanding of the challenges related to poverty alleviation. Unsurprisingly, they have also been met with criticism on conceptual, normative and technical grounds, which have in part contributed to further modification, revision and refinement. The MPI is no exception. It has been argued that it excludes relevant indicators and dimensions of human deprivation, does not measure poverty at the individual level, uses arbitrary cut-off points and does not use adequately grounded participatory research that is sensitive to the views of the poor (see Wisor et al. 2014, Burchi et al. this volume, Chimakonam this volume, and Godinot and Walker this volume). In the MPI's defence it should be noted that some of these problems stem partly from the need to use existing datasets on poverty, which must be comparable across countries in the case of the global MPI. Better and more comprehensive data on the lives of the poor could in future lead to a more plausible and comprehensive MPI. Several contributions to this volume discuss these concerns in much more detail, on conceptual, normative, discursive and technical grounds (Brando and Pitasse Fragoso this volume; Burchi et al. this volume; Chimakonam this volume; Dübgen this volume; Godinot and Walker this volume; and Hassoun et al. this volume). Their underlying goal is to continue to improve our understanding of multidimensional poverty, so that refined multidimensional indexes may provide even more useful complementary frameworks next to monetary measures (see Parts II and IV in this volume).

\section{(b) Research methodologies and epistemic injustices}

Poverty measurement within and across countries not only requires working with justifiable normative assumptions. It also involves gathering empirical data on how individuals fare along poverty's various dimensions. Empirical research should not merely come into play after the determination of poverty indicators; it should play a central role at the earlier stage of designing poverty indexes for different social contexts, because this requires taking account of the particular social conditions of the context in which poverty is measured. Several philosophical insights speak in favour of such an approach. We have already referred to Adam Smith's more general observation that in order to understand poverty one must take note of social customs (see Sect. 2a). Amartya Sen argued in a similar vein, but with more systematic precision, that "absolute deprivation in terms of a person's capabilities relates to relative deprivation in terms of commodities, income and resources" (Sen 1983, p. 153 [italicized as in the original]; see also Dotter and Klasen this volume, and Reddy this volume). Researchers must therefore empirically determine the extent to which 
various kinds of deprivation in different poverty dimensions translate into relative resource deprivations in a given social context. On a more fundamental level, poverty researchers must also take into account that any selection, description and presentation of data is necessarily value-laden (see e.g. Longino 1990).

The selection of poverty dimensions, as well as their indicators, should be an object of ongoing research. Critics of the MPI, for example, have argued that its selection of dimensions and indicators is not based on a comprehensive and justifiable conception of poverty, but is rather reflective of contingent data availability (Wisor et al. 2014, Burchi et al. this volume; Godinot and Walker this volume; and Brando and Pitasse Fragoso this volume). From a philosophical perspective, incomplete data should of course not be allowed to determine the structure of a poverty index. Rather, such an index must be based on a sound and comprehensive conception of poverty which may very well require collecting new data. This need for a normative grounding does not imply, however, that a sound index could be derived by purely philosophical reasoning alone (as opposed to being mostly data-driven). In fact, empirical poverty research that is focussed on the full range of poverty-related deprivations in a given context, as well as on the views of those who live in poverty, is of central importance even on this most fundamental level of poverty research. There are different methods that allow researchers to generate indices along different poverty dimensions and to take into account the context-relative requirements for the realization of capabilities and functionings in these dimensions. Among the proposed methods are ${ }^{4}$ : survey-based approaches, such as in the World Values Survey; public-consensus building, as proposed in the processes leading up to the Millennium Development Goals (MDGs) in 2000 and the SDGs in 2015; participatory poverty assessment, such as that conducted by the "Voices of the Poor" project (see Narayan et al. 2000; for another more recent participatory approach, see Godinot and Walker this volume); and the constitutional approach, which seeks to derive information about poverty dimensions from the content of selected constitutions (see Burchi et al. this volume). Linares and $\mathrm{Su}$ (this volume) propose employment of financial diaries as a complementary method which allows for a better understanding of local cultural and societal dynamics that are hidden in national statistics. Last but not least, country studies, which focus on specific characteristics of a given social context, will of course remain an important form of poverty research (for three different cases, see: Linares and Su this volume; Mpenya et al. this volume; and Keskin this volume). Researchers will continue to debate the relative merits and potential combinations of such approaches to determining the dimensions of poverty. What is certain is that empirical methods need to have a firm normative grounding, for which conceptual analysis and programmatic ideas - such as Sen's plea that poverty-relevant capabilities should be determined via processes of public reasoning - will continue to be relevant.

Beyond methodological questions of research design, these considerations also show that poverty research must be genuinely global in nature, and not just in terms

\footnotetext{
${ }^{4}$ For an overview on the first three types of approaches, among others, see Alkire 2007.
} 
of more comprehensively taking into account the needs and capabilities of the poor across the world. Poverty research must also be more inclusive in terms of who conducts it, as the present exclusion of the views of scholars from the Global South arguably constitutes an epistemic injustice. According to Miranda Fricker, we can distinguish two kinds of epistemic injustice, namely testimonial and hermeneutical injustices. The former occur whenever a speaker's credibility is undervalued due to a morally arbitrary feature such as skin colour or gender, whereas the latter occur at a prior level, insofar as a knower suffers from a lack of collective interpretive resources that would cognitively allow her to analyse a given injustice (see Fricker 2007). Some contributions (in particular Chimakonam this volume and Dübgen this volume) reflect on how the concept of epistemic injustice can be applied to the issue of asymmetries in poverty research. Furthermore, the pluralistic composition of this volume should be seen as an attempt to address such epistemic asymmetries. Demands that these injustices be remedied apply to philosophers and to more empirically oriented scientists alike. Although we, the editors of this volume, are all based in the Global North, we have strived to give space to views from scholars from the Global South. This is not only a question of fairness, we think, but also highly instructive because they address marginalized topics in their own voice (see Sect. 3 below, and in particular Chimakonam this volume and Omotoso this volume).

\section{(c) Responsibilities for poverty alleviation}

In the last three decades, moral and political theorists have increasingly worked with the assumption that the responsibility to alleviate poverty is dependent on the content, scope and weight of norms of social justice. We live in a world that is economically and ecologically highly interdependent - the worsening climate crisis is only the most evident example of this fact. The deprivations of the global poor are causally connected to the shape of political and economic institutions in other contexts, including international institutions related to trade, security and the environment. If poverty is at least in part a result of the institutional design of our current world order, and if this design constitutes a global injustice, then responsibilities to alleviate poverty should not only be conceived on purely humanitarian grounds. Rather, all those who are implicated in or even complicit in these injustices, including the world's affluent people, also have justice-related obligations to address poverty, additional to their humanitarian obligations. The debate on the content, scope and weight of justice-related and humanitarian responsibilities within and across borders is already quite voluminous (see e.g. Pogge and Moellendorf 2008, Brooks 2008, Young 2011). We therefore do not wish to repeat the core debate in this volume. Instead, we would like to accommodate more specific interventions regarding the responsibility for addressing poverty in different contexts. One such aspect is the importance of tying questions of responsibility to those of conceptualizing and measuring poverty (see Lepenies this volume, and Putnam this volume). Furthermore, some of the contributions in this volume conceptualize and problematize the content of "philanthropic" responsibilities for poverty alleviation (see Illingworth this volume, and Mahlert this volume). Last but not least, there is a need for reflection on how to conceive of the role of political theorists themselves with respect to global 
poverty alleviation (see Sengupta this volume). Many philosophers and normative theorists aim to reconcile their academic and political responsibilities. ${ }^{5}$ As a result, some political philosophers have become advocates for political change and ultimately political activists themselves. One may therefore wonder if there is a deeper or even necessary correlation between normative analysis and political engagement.

\section{Previewing the Volume's Structure and Content}

After having given an overview of the anthology's discursive context and central themes, we now introduce its structure and content in more detail. The book is divided in five parts: The contributions in Part I are dedicated to the issue of poverty as a social relation; Part II contains reflections on neglected views and epistemic injustices in poverty research; Part III's contributions discuss the importance of the social context for poverty research; the contributions in Part IV are dedicated to the measurement of multidimensional poverty within development economics; Part V contains three different country studies.

\subsection{Part I: Poverty as a Social Relation}

The contributions by Wolff, Putnam and P. Lepenies all engage with different themes related to the task of understanding poverty as a socially relational concept. The plea for such a relational understanding has roots in the history of Western social and political thought, as detailed by Wolff (this volume) and Lepenies (this volume), but can also be associated with the contemporary debate about social egalitarianism in moral and political theory (see e.g. Fourie et al. 2015, and Hull 2015). Some argue that a relational egalitarian approach also underlies the African philosophy of Ubuntu (see Oelofsen 2018). According to this strand of normative theory, realizing "social equality"- - or "relational equality", as it is also called-does not simply require equal distributions of material and immaterial goods, rights, and freedoms in a given context. Rather, the demand of equal treatment is interpreted as requiring the realization of egalitarian social relationships on a more fundamental level, which creates certain demands on the distributional level. The social egalitarian perspective can also yield a deeper and more compelling analysis of poverty, according to which poverty is not simply a lack of financial resources (see Sect. 2a above). Instead, we must develop a thorough understanding of how economic depri-

\footnotetext{
${ }^{5}$ This is reflected in two more recent philosophical movements: effective altruism (see e.g. Singer 2015) and Academics Stand Against Poverty (see e.g. Pogge and Cabrera 2012).
} 
vations affect social relationships in various negative ways, without neglecting monetary indicators altogether.

In "Beyond Poverty", Jonathan Wolff (this volume) builds on insights from his own earlier works (see Wolff and de-Shalit 2007, Wolff 2015a, b) and argues that a conceptual and pragmatic focus on the alleviation of monetary poverty is insufficient, because it fails to fully capture the precarious social position of people living in poverty. However, working with a narrower concept of poverty alleviation-such as raising incomes-remains helpful, as it facilitates political consensus about the implementation of poverty alleviation measures. In "Poverty as a Social Relation", Daniel Putnam (this volume) argues that understanding poverty as a social relation requires focussing on threats to valuable interpersonal relationships. Further, he reflects on how the range of relational disadvantages that poor people suffer generates, first, general obligations of justice to invest in social capital and relational goods, and second, more specific poverty-related obligations of academics. In "Metrics, Politics and Definitions", Philipp Lepenies (this volume) argues that modern efforts to measure poverty have had the unintended effect of narrowing and "de-socializing" the common understanding of poverty. He contends that an emphasis on absolute poverty remains hegemonic, despite important treatments of poverty as a genuinely relational and socially relative phenomenon, as in the works of Georg Simmel or Peter Townsend.

\subsection{Part II: Epistemic Injustices in Poverty Research}

This part of the book assembles contributions by Dübgen, Chimakonam, Omotoso and Sengupta, which shed light on various epistemic injustices in the debate on global poverty. These contributions bring so-called Northern and Southern perspectives into a fruitful dialogue. Both testimonial and hermeneutical injustices (see Sect. $2 \mathrm{~b}$ above) occur in academic and in more general debates on global poverty, neither of which are sufficiently globalized yet. Whether in policy debates or on the editorial boards of highly regarded academic journals, voices and perspectives from the Global South are often sidelined. It is highly problematic that those who live in global poverty remain largely excluded from its conceptualization. This exclusion also applies to the production of knowledge about effective means of poverty reduction. On the other hand, activists from the Global North are often suspected of pursuing Western interests (see the discussion in Sengupta this volume). We need participatory approaches that not only include the voices of the poor but make them agents of poverty research in their own right, agents who make an essential contribution to the conceptualization, measurement and possible eradication of poverty (see e.g. Laderchi et al. 2006, and Godinot and Walker this volume). The multiperspectivity of this volume can itself be regarded as a modest contribution to epistemic justice in poverty research.

In "Scientific Ghettos and Beyond", Franziska Dübgen (this volume) discusses in detail how researchers from the Global South are structurally excluded from 
global knowledge production and how this constitutes a major epistemic injustice. Dübgen expects that epistemic justice in poverty research is not only an end in itself, as it is required in terms of internal fairness, but that eradicating such injustices would also increase the quality of global knowledge production. In "Is the debate on poverty research a global one?", Jonathan Chimakonam (this volume) reflects on epistemic injustices in global poverty research and examines a concrete case, namely the exclusion of the Kenyan philosopher Odera Oruka from academic exchange. Chimakonam then turns to the constructive idea of conversational thinking, found in African philosophy, defined as an inclusive, fair, horizontal and intercultural engagement for a truly global poverty discourse. In "Hairiness and Hairlessness: An African Feminist view of Poverty", Sharon Omotoso (this volume) reflects on "intellectual poverty", conceptualized as a lack of sufficient education to develop viable ideas for one's own life and society. Omotoso analyses different class-related manifestations of "intellectual poverty" and discusses measures such as joint knowledge production and the overcoming of class protectionism, which could unite differently affected social groups in the fight against poverty. In "Western Academic Activism and Poverty Research", Mitu Sengupta (this volume) reflects on the accusation by post-development critics that Western activism aimed at social and political change in the Global South is at best paternalistic and self-aggrandizing, and at worst represents a relapse into colonial power structures. However, Sengupta argues that the valid concerns of post-development critics basically require more and not less activism on the part of Western scholars, namely activism of the correct, cooperative kind.

\subsection{Part III: Poverty in Context}

It means something different to be poor in Africa, Asia or Europe, and it matters what social position poor people hold vis-à-vis rich people, the state, global institutions or potential benefactors. As it turns out, the social and political context plays a decisive role in determining what poverty is, what kinds of data are relevant and what policies will contribute effectively to its alleviation. The contributions to the third part of this volume, by Illingworth, Schweiger and Mahlert, reflect the relevance of the social and political context for the conceptualization, measurement and alleviation of poverty.

In "Giving Well: Philanthropy for Human Rights", Patricia Illingworth (this volume) stresses the importance of political and ultimately juridical solutions to the global poverty problem and argues that non-state actors, including business actors and philanthropists, should donate to sectors and charitable organisations that address structural human rights deficiencies, in accordance with their "social licence to operate". Illingworth focusses on the human right to health, because efforts to protect it represent a very effective way to fight poverty. In "Absolute Poverty in Europe-What can it mean?", Gottfried Schweiger (this volume) reflects on the fact that even in Europe, there are people—like the sans-papiers and the homeless—who 
would be poor in any society imaginable, because they have too little social security and visibility to lead a life that is respectable in any way. For him the phenomenon of absolute poverty in Europe is reproduced by practices of exclusion, stigmatization and domination, practices that effective policies must target. In "Poverty, Richness, and Aid: A Conceptual Proposal", Bettina Mahlert (this volume) takes into account how social categories such as deprivation, lack, and scarcity-and wealth and abundance as their opposites-not only mark social asymmetries but can also contribute to reproducing them. Mahlert argues against the tendency to describe poverty and wealth in binary terms, and proposes to integrate positive classifications into the description of multidimensional deprivation and the definition of wealth.

\subsection{Part IV: Measuring Multidimensional Poverty}

This part assembles the views of leading development economists and philosophers on current issues in poverty measurement. The contributions by Alkire; Reddy; Klasen and Dotter; Godinot and Walker; Burchi, Rippin and Montenegro; Brando and Pitasse Fragoso; and Hassoun, Herlitz and Esposito shed light on contemporary challenges related to the conception and practical use of various poverty indexes in development economics and politics (for more background on poverty measurement, see Sect. 2a above).

In "Multidimensional Poverty Measures as Policy Tools", Sabina Alkire (this volume) explains the composition of and central ideas behind the Multidimensional Poverty Index (MPI) and details how multidimensional indexes for different social contexts (different countries and globally) provide valuable information that should be used to improve poverty-related policy actions. The first SDG notably calls for ending poverty in all forms and dimensions-and Alkire argues in detail that the MPI represents a useful tool that can help policy makers to reach this goal. In "Poverty: Beyond Obscurantism", Sanjay Reddy (this volume) argues that poverty measurement needs to be based on clear, transparent and appropriate evaluative standards, and that this requirement has not been met in three prominent contexts: (1) global income poverty measurement; (2) measurement of poverty in India; and (3) measurement of poverty in the United States. However, ex negativo, engaging with these three problematic examples reveals how obscurantism in poverty measurement can be avoided and how more accountability can be achieved at the same time. In "An absolute multidimensional poverty measure in the functioning space (and relative measure in the resource space)", Dotter and Klasen (this volume) argue that while some MPI indicators cannot be assessed in relative terms (e.g. health, as it reflects specific health functionings), education and standard of living metrics should be relative. Dotter and Klasen build on the UNDP's Global MPI (Alkire and Santos 2014) and introduce adaptable (resource-related) indicator thresholds which can be fitted to prevailing standards in a given regional context. In "Poverty in All its Forms", Godinot and Walker (this volume) propose a novel, transpositional, transdisciplinary and participatory methodology called "Merging of Knowledge". 
They argue that while multidimensional poverty indicators represent real progress over unidimensional ones, a different form of research is required to identify dimensions of poverty based on experiential knowledge. In "The measurement of multidimensional poverty across countries", Burchi et al. (this volume) argue for a "constitutional approach" (Burchi, De Muro and Kollar) as a theoretical framework for multidimensional poverty measurement. The idea behind this proposal is that the normative assumptions implicit in the construction of multidimensional indexes are to be justified through a systematic and comparative evaluation of national constitutions, which yields a list of three dimensions for international comparisons of poverty, namely health, education and decent employment. In "Agency and the Relational Dimension of Poverty", Brando and Pitasse Fragoso (this volume) discuss how poverty measurement requires context-sensitive methods. In comparing three multidimensional indexes (Human Poverty Index, Multidimensional Poverty Index and the York model), they argue that these models focus on certain forms of capability deprivation while overlooking others. In "Multidimensional Poverty Measurement: The Value of Life and the Challenge to Value Aggregation", Nicole Hassoun et al. (this volume) discuss the necessity and pitfalls of trade-offs between different dimensions of poverty. The contributors argue that the value of life (implied in indexes related to life expectancy or child mortality) should not be simply set off against other dimensions.

\subsection{Part V: Country Cases}

This part of the book contains three country case studies from Africa, Europe and Asia, authored by Mpenya, Baye and Epo; Keskin; and Linares and Su. Each country case demonstrates the importance of a contextual perspective for poverty measurement and evaluation, and shows how citizens, policy-makers and scholars are motivated to grasp the many dimensions of poverty for very different reasons. Whether it is asset endowments along ethnic stratifications in Cameroon, conditions of precarity of denizens in Germany, or patriarchal debt relationships in Bangladesh — each country study goes beyond an empirical investigation of poverty in a given context and links back to systematic questions of how multidimensional poverty should be conceptualized and measured.

In "Mapping Out Multiple Dimensions of Well-Being by Ethnicity in Rural Cameroon", Mpenya et al. (this volume) argue that it is necessary to investigate non-monetary dimensions of poverty in the African context, especially as they relate to ethnic groups. The authors look at different categories of asset endowments (financial, human, natural, physical, social) in order to compare indicators and track multiple dimensions of well-being along four main ethnic groups. In "Rising Tide of Precariat and Denizens in Neoliberal Capitalism: The Case of Germany", Eda Keskin (this volume) describes a specific form of poverty in Germany, namely precarity, defined as a socio-economic condition in which employment is uncertain or intermittent. In Keskin's case study, it is shown that groups at high risk of precarity 
encompass "denizens": migrants, refugees and their children, and others lacking the full rights of citizens (Standing 2014), as well as young adults, single parents, sick or disabled individuals, and retired people, but also academics and working women. In "Measuring Capabilities: Using Financial Diaries in Bangladesh", Linares and $\mathrm{Su}$ (this volume) argue that financial diaries can serve as a fitting methodological complement to multidimensional poverty analyses and statistics. Based on a case study in Kapasia, Bangladesh, they show how financial diaries serve as sociological tools that can provide a rich understanding of debt, transfer and gift networks that either augment or detract from people's abilities to be and do different things.

The methodologies and views assembled in this anthology are rich and diverse. We dare to hope that this diversity and the interdisciplinarity of the volume will be considered a strength. After all, listening to the views and voices of those affected by poverty is key when it comes to advancing the debate on poverty, and that on political and economic efforts at poverty alleviation.

\section{References}

Alkire, Sabina. 2007. Choosing dimensions: The capability approach and multidimensional poverty. In The many dimensions of poverty, ed. Nanak Kakwani and Jacques Silber, 89-119. New York: Palgrave Macmillan.

- this volume. Multidimensional poverty measures as policy tools. In Dimensions of poverty: Measurement, epistemic injustices, activism, ed. Valentin Beck, Henning Hahn, and Robert Lepenies. Berlin/Heidelberg: Springer.

Alkire, Sabina, and Maria E. Santos. 2014. Measuring acute poverty in the developing world: Robustness and scope of the multidimensional poverty index. World Development 59: 251-274.

Alkire, Sabina, Kanagaratnam, Usha, Suppa, Usha. 2018. The Global Multidimensional Poverty Index (MPI): 2018 Revision. OPHI MPI Methodological Notes 46. https://ophi.org.uk/wpcontent/uploads/OPHI_MPI_Meth_Note_46.pdf. Accessed 1 Nov 2018.

Booth, Charles. 1903. Life and labour of the people in London. London/New York: Macmillan.

Brando, Nicolas, and Katarina Pitasse Fragoso. this volume. Capability deprivation and the relational dimension of poverty: Testing universal multidimensional indexes. In Dimensions of poverty: Measurement, epistemic injustices, activism, ed. Valentin Beck, Henning Hahn, and Robert Lepenies. Berlin/Heidelberg: Springer.

Brock, Gillian, ed. 1998. Necessary goods. Our responsibilities to meet others' needs. Lanham: Rowman \& Littlefield.

Brooks, Thom, ed. 2008. The global justice reader. Oxford: Blackwell.

Burchi, Francesco, Nicole Rippin, and Claudio E. Montenegro. this volume. The measurement of multidimensional poverty across countries: A proposal for selecting dimensions. In Dimensions of poverty: Measurement, epistemic injustices, activism, ed. Valentin Beck, Henning Hahn, and Robert Lepenies. Berlin/Heidelberg: Springer.

Chimakonam, Jonathan $\mathrm{O}$. this volume. Is the debate on poverty research a global one? A consideration of the exclusion of Odera Oruka's 'human minimum' as a case of epistemic injustice. In Dimensions of poverty: Measurement, epistemic injustices, activism, ed. Valentin Beck, Henning Hahn, and Robert Lepenies. Berlin/Heidelberg: Springer. 
Dotter, Caroline, and Stephan Klasen. this volume. An absolute multidimensional poverty measure in the functioning space (and relative measure in the resource space): An illustration using Indian data. In Dimensions of poverty: Measurement, epistemic injustices, activism, ed. Valentin Beck, Henning Hahn, and Robert Lepenies. Berlin/Heidelberg: Springer.

Dübgen, Franziska. this volume. Scientific ghettos and beyond: Epistemic injustice in academia and its effects on researching poverty. In Dimensions of poverty: Measurement, epistemic injustices, activism, ed. Valentin Beck, Henning Hahn, and Robert Lepenies. Berlin/Heidelberg: Springer.

Fourie, Carina, Fabian Schuppert, and Ivo Wallimann-Helmer, eds. 2015. Social equality: Essays on what it means to be equals. Oxford: Oxford University Press.

Fricker, Miranda. 2007. Epistemic injustice: Power and the ethics of knowing. Oxford: Oxford University Press.

Godinot, Xavier, and Robert Walker. this volume. Poverty in All its Forms: Determining the dimensions of poverty through merging knowledge. In Dimensions of poverty: Measurement, epistemic injustices, activism, ed. Valentin Beck, Henning Hahn, and Robert Lepenies. Berlin/ Heidelberg: Springer.

Hassoun, Nicole, Anders Herlitz, and Lucio Esposito. this volume. Multidimensional poverty measurement: The value of life and the challenge to value aggregation. In Dimensions of poverty: Measurement, epistemic injustices, activism, ed. Valentin Beck, Henning Hahn, and Robert Lepenies. Berlin/Heidelberg: Springer.

Hickel, Jason. 2016. The true extent of global poverty and hunger: Questioning the good news narrative of the millennium development goals. Third World Quarterly 37 (5): 749-767.

Hull, George, ed. 2015. The equal society. Lanham: Lexington Books.

Illingworth, Patricia. this volume. Giving well: Philanthropy for human rights. In Dimensions of poverty: Measurement, epistemic injustices, activism, ed. Valentin Beck, Henning Hahn, and Robert Lepenies. Berlin/Heidelberg: Springer.

Keskin, Eda. this volume. Rising tide of precariat and denizens in neoliberal capitalism: The case of Germany. In Dimensions of poverty: Measurement, epistemic injustices, activism, ed. Valentin Beck, Henning Hahn, and Robert Lepenies. Berlin/Heidelberg: Springer.

Laderchi, Caterina Ruggeri, Ruhi Saith, and Frances Stewart. 2006. Does it matter that we do not agree on the definition of poverty? A comparison of four approaches. In Understanding human well-being, ed. Mark McGillivray and Matthew Clarke, 19-53. Tokyo/New York: United Nations University Press.

Lepenies, Philipp. this volume. Metrics, politics and definitions: How poverty lost its social context and what this means for current debates. In Dimensions of poverty: Measurement, epistemic injustices, activism, ed. Valentin Beck, Henning Hahn, and Robert Lepenies. Berlin/ Heidelberg: Springer.

Linares, Julio, and Yu-hsuan Su. this volume. Measuring capabilities: Using financial diaries in Bangladesh. In Dimensions of poverty: Measurement, epistemic injustices, activism, ed. Valentin Beck, Henning Hahn, and Robert Lepenies. Berlin/Heidelberg: Springer.

Longino, Helen. 1990. Science as social knowledge: Values and objectivity in scientific inquiry. Princeton: Princeton University Press.

Mahlert, Bettina. this volume. Poverty, richness, and aid: A conceptual proposal. In Dimensions of poverty: Measurement, epistemic injustices, activism, ed. Valentin Beck, Henning Hahn, and Robert Lepenies. Berlin/Heidelberg: Springer.

Mpenya, Hans Tino Ayamena, Francis Menjo Baye, and Boniface Ngah Epo. this volume. Mapping out non-monetary dimensions of Well-being by ethnicity in rural Cameroon. In Dimensions of poverty: Measurement, epistemic injustices, activism, ed. Valentin Beck, Henning Hahn, and Robert Lepenies. Berlin/Heidelberg: Springer.

Narayan, Deepa, Raj Patel, Kai Schafft, Anne Rademacher, and Sarah Koch-Schulte. 2000. Voices of the poor: Can anyone hear us? New York: Oxford University Press.

Nussbaum, Martha. 2000. Women and human development. Cambridge: Cambridge University Press. 
2011. Creating capabilities. The human development approach. Cambridge, MA: Harvard University Press.

Oelofsen, Rianna. 2018. Women and ubuntu: Does ubuntu condone the subordination of women? In African philosophy and the epistemic marginalization of women, ed. Jonathan O. Chimakonam and Louise du Toit, 42-56. London/New York: Routledge.

Omotoso, Sharon Adetutu. this volume. Hairiness and hairlessness: An African feminist view of poverty. In Dimensions of poverty: Measurement, epistemic injustices, activism, ed. Valentin Beck, Henning Hahn, and Robert Lepenies. Berlin/Heidelberg: Springer.

Pogge, Thomas, and Luis Cabrera. 2012. Outreach, impact, collaboration: Why academics should join to stand against poverty. Ethics \& International Affairs 26 (2): 163-182.

Pogge, Thomas, and Darrel Moellendorf, eds. 2008. Global justice. Seminal essays. St. Paul: Paragon House.

Putnam, Daniel. this volume. Poverty as a social relation. In Dimensions of poverty: Measurement, epistemic injustices, activism, ed. Valentin Beck, Henning Hahn, and Robert Lepenies. Berlin/ Heidelberg: Springer.

Rawls, John. 1999 [1971]. A theory of justice, Rev. ed. Cambridge, MA: Belknap Press.

Reddy, Sanjay G. this volume. Poverty: Beyond obscurantism. In Dimensions of poverty: Measurement, epistemic injustices, activism, ed. Valentin Beck, Henning Hahn, and Robert Lepenies. Berlin/Heidelberg: Springer.

Reddy, Sanjay G., and Rahul Lahoti. 2016. 1,90\$ a day: What does it say? New Left Review 97: 106-127.

Reddy, Sanjay G., and Thomas Pogge. 2010. How not to count the poor. In Debates on the measurement of global poverty, ed. Sudhir Anand, Paul Segal, and Joseph Stiglitz, 42-85. Oxford: Oxford University Press.

Rowntree, Benjamin S. 1901. Poverty: A study of town life. London: Macmillan and Company.

Schweiger, Gottfried. this volume. Absolute poverty in European welfare states. In Dimensions of poverty: Measurement, epistemic injustices, activism, ed. Valentin Beck, Henning Hahn, and Robert Lepenies. Berlin/Heidelberg: Springer.

Sen, Amartya. 1981. Poverty and famines. An essay on entitlement and deprivation. New York: Oxford University Press.

1983. Poor, relatively speaking. Oxford Economic Papers 35: 153-169.

1999. Development as freedom. New York: Alfred A. Knopf.

2009. The idea of justice. Cambridge, MA: Belknap Press.

Sengupta, Mitu. this volume. Western academic activism and poverty research: What's not to like. In Dimensions of poverty: Measurement, epistemic injustices, activism, ed. Valentin Beck, Henning Hahn, and Robert Lepenies. Berlin/Heidelberg: Springer.

Singer, Peter. 2015. The most good you can do: How effective altruism is changing ideas about living ethically. New Haven: Yale University Press.

Smith, Adam. 1976 [1776]. An inquiry into the nature and causes of the wealth of nations, ed. R. H. Campbell and A. S. Skinner. Oxford: Clarendon Press/Oxford University Press.

Standing, Guy A. 2014. A precariat charter: From denizens to citizens. London: A\&C Black.

Townsend, Peter. 1954. Measuring poverty. The British Journal of Sociology 5: 130-137.

1979. Poverty in the UK: A survey of household resources and standards of living. Harmondsworth/New York/Ringwood/Markham/Aukland: Penguin Books Ltd.

Wisor, Scott, Sharon Bessel, Fatima Castillo, Joanne Crawford, Kieran Donaghue, Janet Hunt, Alison Jaggar, Amy Liu, and Thomas Pogge. 2014. The individual deprivation measure. A gender-sensitive approach to poverty-measurement. Melbourne: International Women's Development Agency. http://www.individualdeprivationmeasure.org/resources/arc-report/. Accessed 1 Nov 2018.

Wolff, Jonathan. 2015a. Social equality and social inequality. In Social equality: Essays on what it means to be equals, ed. Carina Fourie, Fabian Schuppert, and Ivo Wallimann-Helmer, 209226. Oxford: Oxford University Press. 
2015b. Social equality and relative poverty. In The equal society, ed. George Hull, 21-41. Lanham: Lexington Books.

- this volume. Beyond poverty. In Dimensions of poverty: Measurement, epistemic injustices, activism, ed. Valentin Beck, Henning Hahn, and Robert Lepenies. Berlin/Heidelberg: Springer.

Wolff, Jonathan, and Avner de-Shalit. 2007. Disadvantage. Oxford: Oxford University Press.

World Bank. 2018. Poverty and shared prosperity 2018: Piecing together the poverty puzzle.

Washington, DC: World Bank.

Young, Iris M. 2011. Responsibility for justice. Oxford: Oxford University Press.

Open Access This chapter is licensed under the terms of the Creative Commons Attribution 4.0 International License (http://creativecommons.org/licenses/by/4.0/), which permits use, sharing, adaptation, distribution and reproduction in any medium or format, as long as you give appropriate credit to the original author(s) and the source, provide a link to the Creative Commons licence and indicate if changes were made.

The images or other third party material in this chapter are included in the chapter's Creative Commons licence, unless indicated otherwise in a credit line to the material. If material is not included in the chapter's Creative Commons licence and your intended use is not permitted by statutory regulation or exceeds the permitted use, you will need to obtain permission directly from the copyright holder.

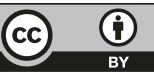

